\section{A ANTIDOPAGEM EM FACE DAS DEMANDAS DA AGÊNCIA MUNDIAL: UMA ETNOGRAFIA DA 'CONFORMIDADE' EM AÇÃO}

ANTI-DOPING FACED WITH THE DEMANDS OF THE WORLD AGENCY: AN ETHNOGRAPHY OF 'COMPLIANCE' IN ACTION C

EL ANTIDOPAJE FRENTE A LAS DEMANDAS DE LA AGENCIA

MUNDIAL: UNA ETNOGRAFÍA DE LA ‘CONFORMIDAD’ EN ACCIÓN C己

doi' https://doi.org/10.22456/1982-8918.111756

(D) Daniel Giordani Vasques* <dgvasques@hotmail.com>

(D) Mauro Myskiw* <mmyskiw@hotmail.com>

Patrick Trabal** <ptrabal@parisnanterre.fr>

Marco Paulo Stigger* <stigger.mp@gmail.com>

\footnotetext{
*Universidade Federal do Rio Grande do Sul. Porto Alegre, RS, Brasil.

**Université Paris Nanterre. Nanterre, França.
}

Recebido em: 25 fev. 2021 Aprovado em: 12 jun. 2021 Publicado em: 12 jul. 2021

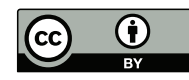

Este é um artigo publicado sob a licença Creative Commons Atribuição 4.0 Internacional (CC BY 4.0).

eISSN: 1982-8918 


\section{INTRODUÇÃO}

Questões relacionadas ao doping e ao anti-doping têm mobilizado pesquisadores das Ciências Sociais e Humanas, como indica a existência do grupo na Universidade de Lausanne, na Suíça, o grupo Sciences Sociales et Dopage na Universidade Paris Nanterre, na França, e a International Network of Doping Research, que agrega instituições de diferentes países, sediada na Universidade de Aarhus, na Dinamarca. No Brasil, mesmo não havendo uma articulação institucional como essas, notamos um conjunto de pesquisadores interessados em diferentes temáticas, entre eles Silva (2005), Vaz (2005), Pereira e Gleyse (2005), Devide e Votre (2005), Silveira e Rigo (2015).

Em que pesem os debates existentes, o presente trabalho trata da constituição de agências e de políticas antidopagem no esporte, com enfoque sobre ações de governança institucionais. Ele vem na esteira da temática abordada por Hanstad, Smith e Waddington (2008), sobre o estabelecimento da Agência Mundial Antidopagem (WADA ${ }^{1}$ ) e de como o Comitê Olímpico Internacional (COI) procurou administrar e se posicionar nesse processo. Aprofundando o estabelecimento dessa Agência, Demeslay (2013) se dedicou a estudar a harmonização de regulamentos e atores plurais, desde o anúncio da criação da WADA, interessada em compreender a passagem de um estado inicial anterior para o desejo político de pôr fim a uma diversidade de práticas antidopagem realizadas até então. Seu trabalho mostra como essa passagem incluiu a necessidade de convocar atores para harmonizar, elaborar as regulamentações, evoluir seus regulamentos, operar com as dificuldades para sua aplicação etc.

Noutro estudo, Demeslay (2016) avança sobre a temática da governança global e da harmonização da luta anti-doping orientada por um código que provém de uma fundação privada (a WADA) que procura se aliar a aparatos estatais. A partir das pesquisas dessa autora, fica claro que o trabalho de harmonização não pode ser reduzido a noções como unificação, uniformização, padronização, coordenação etc., pois se trata de processos sociais complexos através dos quais a governança global é coletivamente praticada. Ela ressalta que essa figura-trabalho de harmonização está ancorada principalmente em casos contenciosos ou suscetíveis a gerar disfunções ao longo do espaço e do tempo.

A harmonização tecida pelos protagonistas opera como um controle deslizante (DEMESLAY, 2013, p.487) que, na passagem de um estado inicial para o desejo político de pôr fim a uma diversidade de práticas, se movimenta por/entre dois cursores. $\mathrm{O}$ primeiro oscila entre estabilidade e reversibilidade, criando a possibilidade de recuar nas decisões tomadas, voltando atrás nas escolhas feitas. Isso é identificado como maneira de reparar situações consideradas imperfeitas, coisas perdidas no contexto, como também uma abertura para questões que estão por vir. Permite tempo para os atores testarem os dispositivos de harmonização, antes de fazê-los evoluir ou não. Contudo, essa reversibilidade que abre espaço para os atores escaparem da autoridade, de uma relação de dependência, de uma regra. O segundo oscila entre

1 World Anti-Doping Agency (WADA). 
independência e restrição, partindo da ideia institucional de criação e fomento de uma comunidade antidopagem composta de elementos heterogêneos, na qual os protagonistas estão inclinados a aceitar a imposição de procedimentos se puderem manter certa autonomia no cotidiano de suas ações. Daqui emergem concessões, modos de governança particulares que tendem a favorecer atores capazes de construir alvos comuns e, assim, alimentar disparidades.

Nesse contexto da governança antidopagem, inspirados no exercício investigativo empreendido por Demeslay $(2013,2016)$ sobre a harmonização como figura-trabalho a ser compreendida, passamos a nos interessar sobre a dimensão da conformidade das Organizações Nacionais Antidopagem (NADOs²) em relação aos elementos dispostos no Código Mundial Antidopagem (WADA, 2015). A WADA, associada à Organização das Nações Unidas para a Educação, a Ciência e a Cultura (UNESCO $)^{3}$, tem a prerrogativa de classificar as NADOs como "em conformidade" ou em "não conformidade", sendo que aquelas classificadas como "não conformes" não podem realizar ações de controle antidopagem ${ }^{4}$ e nem podem se candidatar para organizar grandes eventos.

Esse nosso interesse tendo a conformidade como noção nativa e objeto de estudo emerge a partir de duas provocações. A primeira relacionada ao estudo de Houlihan (2014) acerca da implementação do Código Mundial Antidopagem por países e governos, com a participação da UNESCO, considerando a distinção entre as dimensões de adesão, implementação e conformidade. Nessa pesquisa, o autor analisa as ferramentas utilizadas pela WADA e pela UNESCO para avaliar a conformidade e conclui que tais ferramentas são melhores para avaliar a implementação formal e não dão conta de fazer o mesmo, com profundidade, em relação ao estabelecimento da conformidade. Nesse mesmo campo de investigação, Zubizarreta e Demeslay (2020) analisaram as relações de poder entre a WADA e as NADOs com base em estudos etnográficos em oito países. Eles mostraram que as NADOs tinham pouco poder de decisão dentro da WADA e que as decisões tomadas pelas agências nacionais nem sempre eram vistas de modo positivo, destacando que a conformidade tem se tornado o objetivo principal de algumas agências nacionais.

A segunda provocação tem relação com a constituição, no Brasil, em 2011, da Autoridade Brasileira para Controle de Dopagem (ABCD), um aparato do Estado (uma NADO) que visa fazer que o sistema antidopagem seja amplamente aplicado no Brasil e que os resultados dos eventos esportivos que aqui ocorrem possam ser legitimados, o que se efetiva se o país-NADO estiver em conformidade. Anteriormente à criação da $A B C D$ as práticas antidopagem estavam baseadas nas ações de entidades esportivas privadas, com destaque para o Comitê Olímpico Brasileiro (COB) e as Confederações Nacionais. Contudo, entre os compromissos assumidos pelo país em 2009 para sediar os Jogos Olímpicos e Paralímpicos do Rio de Janeiro em 2016 (Rio2016) estava a criação de uma NADO brasileira independente das entidades esportivas. Assim, a ABCD foi criada como uma Secretaria Nacional na

\footnotetext{
2 National Anti-Doping Organizations (NADOs).

3 A WADA é composta e sustentada financeiramente pelos Estados-nação (a partir da UNESCO) e pelas instituições esportivas (a partir do movimento olímpico). https://www.wada-ama.org/en/funding

4 Termo nativo que representa as ações de coleta de urina e/ou sangue dos atletas.
} 
estrutura do então Ministério do Esporte (BRASIL, 2011), financiada com recursos públicos. Porém, suas ações deveriam ter independência e autonomia, como é exigido de uma NADO.

Então, se estávamos, de um lado, diante de estudos que apontavam para os desafios da conformidade na governança antidopagem e, de outro, frente à criação da ABCD como NADO brasileira, passamos a investigar ações desenvolvidas entre 2009 e $2017^{5}$ para a transformação de práticas internacionais de antidopagem em arranjos nacionais de antidopagem, esses produzidos na relação com a governança internacional, as quais foram intensamente anunciadas como "políticas de jogo limpo" e/ou de "desenvolvimento da cultura antidopagem". Para abordar esse fenômeno de transformação (no sentido de translação) de protocolos/códigos internacionais em políticas nacionais, passamos a investigar como eles circulavam ao longo de uma cadeia de interesses, perdendo algumas propriedades e ganhando outras para produzir arranjos mais estáveis e reconhecidos como em conformidade, ainda que temporariamente.

Assim, na mesma linha de Demeslay $(2013,2016)$, que toma a harmonização como um figura-trabalho, nosso objetivo, no presente texto, foi descrever atores em ação no trabalho de constituição da conformidade da ABCD em face do imperativo de justificação e captura ativado pela WADA, rastreando associações heterogêneas que procuraram transformar o trabalho de governança global da WADA e, no Brasil, as práticas anteriores conduzidas pelas entidades esportivas privadas numa política nacional antidopagem a partir de uma Secretaria de Estado, tendo em vista a realização dos Jogos Olímpicos e Paralímpicos Rio 2016 e o desenvolvimento de uma "cultura antidopagem". Nos concentramos no período que antecede aos Jogos, pois esse foi um período marcado por uma possível não conformidade da $A B C D$ e uma pressão muito forte diante da chegada das competições associada à tensão política com o impeachment da presidenta do país.

A questão da conformidade é muitas vezes vista como uma exigência de um ator (WADA), uma ameaça (as consequências de uma não conformidade são cada vez mais importantes), eventualmente uma questão legal se surgirem disputas, mas raramente analisada como um processo social complexo marcado por tensões sujeitas a temporalidades específicas. Começa na forma de compromissos firmados: NADOs e o movimento esportivo com WADA, Estados com UNESCO, WADA com Tribunal Arbitral do Esporte, UNESCO com WADA etc. Quando um país se candidata para sediar um grande evento esportivo, outros compromissos são assumidos. A contratualização se constrói em diferentes temporalidades: a da promessa, a da organização do evento, a dos atores com os quais os demais protagonistas estão comprometidos. Em 2009, ficou decidido que o Rio de Janeiro poderia sediar os Jogos Olímpicos se o Brasil se comprometesse a constituir uma NADO independente, a respeitar o Código Mundial Antidopagem e, portanto, a implementar um conjunto de ações ditadas pela WADA. Propomos trabalhar a conformidade "em ação", como Latour analisa a atividade científica em funcionamento. Concretamente, propomos descrever o que os atores fazem para implantar, por um prazo determinado, os

5 A definição desse período considerou que o trabalho de constituição de conformidade esteve especialmente aberto à pesquisa - como controvérsia - entre o ano de 2009, quando a cidade do Rio de Janeiro foi anunciada como sede dos Jogos, até o ano de 2017, quando ocorreram alterações na composição da ABCD. 
dispositivos antidopagem de acordo com o que se comprometeram a fazer. Seguir o processo de conformidade demanda dar conta do trabalho dos atores que cumprem ou não uma promessa e, se necessário, pressionar para que a promessa seja cumprida, ou mesmo sancionar se não o for.

\section{METODOLOGIA}

A pesquisa foi realizada na relação com a sociologia pragmática, operando com a noção de translação presente em obras de Latour $(1994,2000)^{6}$, o que significa seguir essa transformação e como ela aconteceu, envolvendo atores heterogêneos, humanos e não humanos, alistados ou que se alistaram em face dos seus interesses. Transladar, para Latour (2000), significa, também, oferecer novas interpretações dos interesses dos atores alistados, canalizando as pessoas para direções diferentes, num movimento lento de um lugar para outro. Isso implica uma cadeia de traduções simétricas que pode envolver as necessidades de: aliar pessoas com interesses que se movem na mesma direção; lidar com pessoas e interesses muito fortes e poderosos; se aliar a outros interesses como atalho, fazendo desvios de bloqueios; remanejar os interesses e objetivos iniciais; e passar pela posição dos aliados e ajudá-los a promover seus interesses.

A translação investigada envolveu a tarefa difícil de alistar, conectar e manter juntos os atores heterogêneos e seus interesses, mais ou menos alinhados e estabilizados em face de uma política nacional antidopagem e de uma agência brasileira em conformidade. Para fazer isso, na linha da sociologia das associações da obra de Latour $(2001,2012)$, foi preciso olhar para aqueles atores que figuraram como pontos de passagem ou porta-vozes, isto é, aqueles que, como mediadores ${ }^{7}$, produziam performações fortemente engajados ou acionados no alistamento, na conexão e manutenção dos outros atores e seus interesses, diante de inúmeras necessidades que se apresentam. Assim, nesta pesquisa, trabalhamos a partir das performações de dois atores brasileiros que se mostraram ser esses mediadores: João Pedro Wurtz, que atuou na primeira gestão da ABCD; e Ronaldo Deschamps, referência da antidopagem no país, antes da $A B C D$, e membro da organização dos controles nos Jogos Olímpicos e Paralímpicos de $2016^{8}$.

Interessados pela crítica e pelos julgamentos desses mediadores, outra decisão foi a de estudar momentos de provas coletivas ao longo do tempo em busca da conformidade brasileira. Isso, na obra de Latour (2012), seguindo uma abordagem das ciências e das técnicas, é ocupado pela ação de se debruçar sobre as controvérsias, em especial sobre como elas se abrem ou como são encerradas, já que quando estão fechadas elas se assemelham a uma caixa-preta e, portanto, as ações estão pouco visíveis. Para o autor, são as controvérsias que produzem dados empíricos rastreáveis acerca dos movimentos de translação, ou seja, é precisamente

\footnotetext{
6 Para aprofundamento dos vínculos de Latour com a sociologia pragmática, ver Barthe et al. (2016).

7 São os actantes que induzem outros a fazer coisas (que "fazem fazer"), são os porta-vozes. Segundo Latour (2012, p. 65), eles "[...] não podem ser contados como apenas um, eles podem valer por um, por nenhuma, por várias ou uma infinidade. O que entra neles nunca define exatamente o que sai; sua especificidade precisa ser levada em conta todas as vezes. Os mediadores transformam, traduzem, distorcem e modificam o significado ou os elementos que supostamente veiculam."

8 Os nomes dos interlocutores-protagonistas foram substituídos.
} 
através delas que podemos mapear e descrever os trabalhos dos mediadores (dos porta-vozes, dos actantes), transformando, traduzindo, distorcendo e modificando interesses em diferentes situações.

Para a análise das relações de poder entre a ABCD e a WADA, utilizaremos também do conceito de "captura" (emprise) desenvolvido por Chateauraynaud (2006, 2017), o qual apresenta a figura do "capturador", que é responsável por criar assimetrias de aderências (prises) nas relações com os atores. Essas assimetrias, difíceis de localizar e descrever, permitem reter os atores ao longo do tempo ao mesmo tempo em que distanciam o capturador das críticas.

A produção de dados sobre as controvérsias e os atores considerados pontos de passagem ocorreu por meio de uma etnografia multissituada, modo de investigação que, segundo Marcus (2001), emerge da dificuldade ou impossibilidade de conferir contornos de um grupo, isso associado à impossibilidade de distinção entre global-local, e à necessidade de outras formas de imersão e de experiência quando a produção dos objetos investigados atravessa muitas localidades, sendo, portanto, móvel, existente por fluxos.

Com base nessas referências, o primeiro autor desse texto desenvolveu negociações e imersões no mundo da antidopagem esportiva (VASQUES, 2018), principalmente a partir da formação e atuação como um agente de controle de dopagem, cujas experiências foram registradas em diários de campo. Cabe ressaltar que, na perspectiva da etnografia, essa imersão foi realizada em conjunto e em relação com a construção da pesquisa, sendo assim, o pesquisador não tinha experiência anterior com a antidopagem. Desse modo, foi-lhe necessário se familiarizar com o estranho, além de aprender a como situar-se, como olhar, escrever e e conviver com os interlocutores no universo investigado. Isso foi construído, inicialmente, a partir de documentos formais (cartas de apresentação e termos de consentimento livre e esclarecido), mas mantidos e consolidados cotidianamente através de explicações e renegociações sobre a presença, permanência e a participação do pesquisador.

Também foram realizadas entrevistas formais semiestruturadas com 16 atores da antidopagem, incluídos aí os dois mediadores indicados anteriormente. Esse grupo de interlocutores foi composto por secretários nacionais e coordenadores do antidoping da Rio2016, funcionários da ABCD, membros de laboratório antidopagem, além de outros trabalhadores, todos considerados mediadores na antidopagem e que aceitaram participar da pesquisa. As entrevistas foram realizadas presencialmente em diferentes cidades (Brasília, Florianópolis, Lisboa, Porto Alegre, Rio de Janeiro e São Paulo), considerando a disponibilidade dos atores.

Ainda, fizeram parte da investigação documentos nos formatos de leis, normas, códigos e protocolos nacionais e internacionais sobre antidopagem publicados pela ABCD e pela WADA no período de 2009 a 2017, selecionados pela sua relevância e contribuição na descrição das ações e associações dos atores, em que pese as demandas desta pesquisa sobre o movimento de translação. Os documentos utilizados foram: o código mundial (WADA, 2015); e código brasileiro (BRASIL, 2016c); um relatório da WADA (2016) sobre os Jogos de 2016; o Relatório de Observadores Independentes; além de dois decretos e uma lei nacional, que possibilitaram a criação e 
a alteração da composição da ABCD (BRASIL, 2011; 2016a; 2016b). Tais documentos foram fontes de informação que, em triangulação com as entrevistas e as observações empíricas, auxiliaram a descrever as ações dos atores.

$\mathrm{Na}$ produção da empiria pelas observações participantes, entrevistas semiestruturadas e seleção de documentos, a pesquisa seguiu parâmetros de integridade em pesquisas científicas, assim como seguiu procedimentos éticos de investigação. O estudo foi previamente aprovado pelo Comitê de Ética da Universidade Federal do Rio Grande do Sul número protocolo CAAE 63101516.2.0000.5347, Número do Parecer: 2.081.732.

Em termos de resultados dessa pesquisa empírica, considerando a perspectiva teórico-conceitual elencada, apresentamos o trabalho da conformidade como performação imersa num imperativo de justificação e captura ativado para produzir aderências, o que perpassa por importantes momentos de prova aqui descritas como narrativas de associações heterogêneas num leque de controvérsias nas quais os mediadores seguidos se meteram. Isso significa que a conformidade apresentada abaixo como um conceito teórico-acadêmico não tem um desígnio categorial de encerrar ou circunscrever uma questão, pelo contrário, ele procura destacar agenciamentos ao longo do tempo e do espaço, fazendo isso a partir de uma narrativa que descreve os atores fazem alguma coisa e induzem outros a (deixar de) fazer coisas em encruzilhadas que produzem/encontram, num movimento específico de translação.

\section{O TRABALHO DA CONFORMIDADE}

Para sustentar o trabalho da conformidade, o texto a seguir trata de descrever as ações e associações dos atores, destacando dois porta-vozes, em face de dois momentos de prova: o primeiro relacionado aos interesses da WADA e do COI que se deparam com dois grupos atuando na antidopagem no país, o que resultou na elaboração da primeira seção (interesses reunidos, mas não unidos para os Jogos Rio 2016); o segundo destacando como a coexistência e atuação desses dois grupos antidopagem, mostrando a flexibilidade da WADA para a manutenção da conformidade, o que resultou na segunda seção (interesses indispensáveis - mas nem tanto - para os Jogos Rio 2016).

\subsection{A CRIAÇÃO E FUNCIONAMENTO DA ABCD: INTERESSES REUNIDOS, MAS NÃO UNIDOS PARA OS JOGOS RIO 2016}

As relações entre a WADA e o Estado brasileiro foram intensificadas no ano de 2009, a partir do momento em que se anuncia o Rio de Janeiro como cidade-sede dos Jogos Olímpicos de 2016. O texto em sequência procura mostrar as formas como ocorreram essas associações, e como, por fim, a ABCD se distanciou e foi distanciada dos Jogos de 2016 a partir do ingresso de um outro ator: o Comitê Organizador Local da Rio 2016 (COL), uma empresa que recebia recurso estatal e facilidade de financiamento com o propósito de organizar os Jogos. Nos interessa destacar como a WADA se posicionou diante das instituições brasileiras, sobretudo da $A B C D$, favorecendo uma relação de pressão, fiscalização e cobrança. 
Tal relação de poder entre os atores pode ser lida a partir da noção de captura (CHATEAURAYNAUD, 2017). Com base em tal análise social, é possível observar a relação da WADA com a ABCD como uma relação de captura, na qual a aderência à conformidade auxiliaria no processo de assimetria entre os atores, especialmente ao ser construída como um imperativo de justificação ativado pelo capturador. As cenas a seguir mostram como a relação de poder entre esses atores institucionais foi construída também a partir da ativação da conformidade.

O primeiro contato da agência mundial com o Estado brasileiro, especificamente com João Pedro Wurtz - então dirigente da Secretaria Nacional de Esporte de Alto Rendimento do Ministério do Esporte - ocorreu em setembro de 2009, dias antes da escolha do Rio como sede dos Jogos. Esse dirigente público foi entrevistado no transcurso desta pesquisa ${ }^{9}$ e, segundo ele, a WADA visitou os quatro países-sede (as cidades Rio de Janeiro, Chicago, Madri e Tóquio) que estavam concorrendo na época, com o intuito de rever com os respectivos governos as responsabilidades. Segundo Wurtz, o país fez duas promessas:

[...] ter uma NADO e ter um laboratório acreditado pela WADA na cidadesede dos Jogos. Eram responsabilidades do país e, no caso do Brasil, $100 \%$ do governo. Foi a única coisa que o governo assumiu $100 \%$ da responsabilidade [...] de tudo nos Jogos (Entrevista com João Pedro Wurtz).

A importância para a WADA de haver uma agência nacional no país-sede se dava porque considerava fundamental ter uma agência independente, a qual formaria profissionais habilitados para trabalhar com antidopagem atuando nos Jogos (especialmente no cargo de Oficial de Controle de Dopagem - Doping Control Officer - DCO), e também possibilitaria a criação de uma cultura antidopagem no país-sede. A ABCD nasce, portanto, a partir da demanda da WADA e é organizada sobretudo por Wurtz, membro do Ministério do Esporte, que nomeou a partir de sua rede de relações os membros da agência, atores sem experiência na antidopagem e, portanto, distantes das práticas anti-doping realizadas anteriormente no país por empresas privadas e por federações esportivas.

No entanto, a responsabilidade pela organização e pelo planejamento dos controles antidopagem nos Jogos Olímpicos não foi estabelecido como função da organização nacional antidopagem, mas sim de uma comissão formada dentro do COL. Esse Comitê foi liderado por pessoas ligadas historicamente às instituições esportivas privadas brasileiras, e não à ABCD. Por exemplo, Carlos Arthur Nuzman, que foi presidente do Comitê Olímpico Brasileiro (COB) de 1995 a 2017, era também o presidente do COL; assim, foi uma opção do COL que as pessoas convidadas a compor a Comissão Anti-doping da Rio2016 fossem aquelas que realizavam controle anti-doping antes da construção da agência brasileira (2009), e que não tinham, então, relações próximas com atores que atuavam pela NADO brasileira.

Tal Comissão Anti-doping havia sido formada inicialmente por três oficiais de controle de doping experientes, que acabaram por abandoná-la no último ano antes dos jogos. Também entrevistado no transcurso desta investigação ${ }^{10}$, Deschamps relatou

9 Entrevista realizada em Brasília em 11/08/2017 com duração de 04h51min.

10 Entrevista realizada em Porto Alegre em 27/07/2017 com duração de 01h24min. 
que, nesse momento, Nuzman e seus assessores convidaram-no para compor tal Comissão. Ele havia atuado em instituições nacionais antidopagem anteriores à $A B C D$, especificamente na Agência Nacional Anti-doping (ANAD) e na Agência Brasileira Antidoping $(\mathrm{ABA})^{11}$, e não tinha nenhuma proximidade com a NADO brasileira atual, a $A B C D$. Deschamps afirmou que se sentiu em uma "obrigação de assumir" essa função por ter trabalhado juntamente a essas pessoas por muitos anos. Esteve efetivamente próximo ao $\mathrm{COB}$ e às instituições esportivas durante a sua carreira na antidopagem. Ele, por sua vez, convidou pessoas experientes e que eram próximas de seu grupo para trabalhar na Comissão, as quais situavam-se distantes da ABCD.

No último ano antes dos Jogos havia reuniões mensais para tratar dos controles anti-doping, das quais participavam, segundo interlocutores, representantes da WADA, do COI, do COL (Rio2016) e da ABCD. Um dos conflitos principais entre a $A B C D$ e o $C O L$ girou em torno da utilização ou não dos oficiais de controle formados pela autoridade brasileira. O COL admitia utilizar alguns DCOs novos formados pela $A B C D$, mas esta queria que a maioria deles fosse utilizada ${ }^{12}$. No trabalho de campo, foi possível observar conversas, debates, reclamações e questionamentos dos DCOs sobre os convites terem sido feitos sobretudo aos DCOs formados antes da ABCD, controvérsia que mostrou os atores em ação de dois grupos: COL/COB e ABCD. O grupo do COL da Rio2016 tinha interesse em mostrar que tinha capacidade, autoridade e legitimidade para liderar o anti-doping no Brasil. Assim, argumentava que a agência nacional não precisava ter formado tantos DCOs, como havia feito. A WADA interveio e solicitou que o $C O L$ utilizasse oficiais formados pela $A B C D$. A respeito disso, Deschamps afirmou que praticamente todos os DCOs da ABCD trabalharam nos Jogos, e que somente ficaram de fora aqueles que não tinham experiência. Porém, segundo interlocutores que faziam parte da $A B C D$ à época, a maioria dos $D C O$ s não havia sido convidada a atuar, o que foi confirmado por dirigentes do COL.

Essa controvérsia sobre os DCOs possibilitou olhar para os interesses dos grupos que se aliavam em torno da coordenação dos controles antidopagem do país, lugar representado, além da Comissão Anti-doping da Rio2016, pelo comando da $A B C D$. Ao ser entrevistado durante a pesquisa de campo, Deschamps afirmou que coordenar a $A B C D$ não era de seu interesse, porém, era de atores com quem ele havia trabalhado anteriormente à $A B C D$, já que alguns deles assumiram a ABCD em 2016 após o impeachment ${ }^{13}$ da presidenta Dilma Rousseff, do Partido dos Trabalhadores (PT), e a mudança de governo com a presidência assumida por Michel Temer, do Partido do Movimento Democrático Brasileiro (PMDB). Os modos de associação aqui são caracterizados por uma anterioridade do trabalho realizado em conjunto.

Com essa descrição, queremos destacar que a $A B C D$ foi constituída no país sem incluir as pessoas que já trabalhavam com isso há décadas; dessa forma, pudemos notar que esse embate sobre os DCOs ocorreu em um ambiente já

11 Instituições anteriores à ABCD e interligadas ao $\mathrm{COB}$ e, assim, às federações esportivas.

12 Aproximadamente 150 DCOs trabalham na Olimpíada e 70 nos Paralímpicos. Alguns vieram de outros países, porém a maioria era de brasileiros.

13 O processo de impedimento de Dilma Rousseff (PT) iniciou em dezembro de 2015 na Câmara de Deputados. Em 12/05/2016 o Senado Federal aprovou a abertura do processo, o que implicou seu afastamento do cargo e a assunção interina do vice-presidente Michel Temer (PMDB). Em 31/08/2016 o impedimento definitivo foi aprovado. 
conflituoso entre os grupos e seus interesses. Segundo Wurtz, os antigos dirigentes do anti-doping, como Deschamps, não foram convidados a participar da agência por recomendação da WADA, cujos representantes teriam dito repetidamente que o antidoping no Brasil era, antes da ABCD, "terra de ninguém" - ou seja, que os controles eram realizados em desacordo com as normas do Código Mundial. Wurtz, ao alistar seus aliados (WADA e governo brasileiro), conseguiu se manter como dirigente da $A B C D$ (lugar no qual permaneceu por mais de cinco anos), mantendo o controle sobre a antidopagem brasileira e distanciando Deschamps da agência.

Por sua vez, Deschamps afirmou que o COI, responsável pelos Jogos, não queria a $A B C D$ fazendo parte da organização, o que foi confirmado por Wurtz. Dessa forma, a agência nacional não teria a função de organizar o anti-doping nos Jogos, o que acabou sendo função da Comissão Anti-doping do COL Rio2016. Portanto, havia nesse período de preparação para os Jogos dois grupos antidopagem no Brasil; porém, afora esse período, era o grupo de Wurtz que detinha legitimidade e legalidade, via WADA e com o apoio do Ministério do Esporte, para ser a única autoridade antidopagem no país.

Assim, as quatro instituições presentes nas reuniões preparatórias para os Jogos Olímpicos (WADA, COI, COL Rio2016, ABCD) possuíam laços que as uniam, mas também mostravam distanciamentos entre elas. Enquanto o $\mathrm{COI}$ e a Rio2016 estavam preocupados especificamente com os Jogos, esse evento era pontual para a WADA e a $A B C D$, que são instituições antidopagem. Já o COI é uma instituição esportiva e o COL da Rio2016 era uma instituição temporária com raio de ação amplo no que se refere à estrutura e organização de um evento internacional.

Oscilando entre a independência das instituições e as restrições implicadas na luta pela coordenação dos processos, em que pese a realização dos Jogos Olímpicos e Paralímpicos, a ABCD, apesar de maior autoridade nacional, acabou ocupando apenas um lugar de apoio (especialmente com o fornecimento de DCOs) em face das demandas da WADA, a quem cabia as observações e avaliações dos controles antidoping. Como foi observado durante os Jogos, a Comissão Anti-doping do COL Rio2016, da qual Deschamps fazia parte, é que assumiu o protagonismo no planejamento, coordenação e execução dos controles, fazendo isso sobretudo em vista dos interesses do $\mathrm{COB}$ e do $\mathrm{COI}$. Enquanto os interesses do COL consistiam nesse protagonismo, os interesses da $A B C D$ estavam relacionados à conformidade e à legitimidade das suas ações no país. A noção de comunidade antidopagem não teve ressonância, prevalecendo os embates dos interesses de cada grupo reunidos, mas não efetivamente unidos, já que os protagonistas estavam inclinados a participar caso pudessem manter certa autonomia.

Não por acaso o relatório emitido pelos Observadores Independentes da WADA (2016) $)^{14}$ trouxe críticas detalhadas sobre 'o controle antidoping' nos Jogos Olímpicos de 2016. A mídia estrangeira, mais atenta ao universo da dopagem no esporte e habituada a discutir sobre este tema conferiu ressonância a essas críticas.

14 Os observadores independentes da WADA acompanham os controles antidoping de grandes eventos esportivos, como uma consultoria independente que avalia para melhorar as práticas. 
O jornal britânico Telegraph ${ }^{15}$ afirmou que este havia sido o pior controle dos Jogos Olímpicos na história. Entre os argumentos que reforçaram a crítica ao antidoping dos Jogos, constam: falta de hotéis para os DCOs; inexistência de treinamento anterior para os DCOs, como se fez em outros Jogos Olímpicos; falta de verbas para a construção de estruturas, devido à crise político-financeira e à "Operação Lava Jato", que impediram empresas acusadas de desenvolverem obras; além de problemas de alimentação e transporte para os DCOs; bem como falta de escoltas ${ }^{16}$.

Parte dessas críticas mostradas no relatório de observadores e divulgadas pela mídia pôde ser observada na participação no trabalho de campo durante o evento e também foi relatada em conversas informais nos corredores dos Jogos. Um DCO que atuou nos Jogos Olímpicos relatou, em conversa informal, que vários DCOs tiveram que trocar de hotel algumas vezes durante os Jogos. Nos Jogos Paralímpicos, foi possível observar que vários DCOs chegaram à cidade e iniciaram a atuação sem treinamento anterior. A falta de escoltas também foi percebida na pesquisa de campo (observação participante); não eram poucos os dias em que esses trabalhadores, voluntários, eram escassos e o próprio DCO tinha que acumular o trabalho de escolta.

Deschamps defendeu-se ao afirmar que os problemas eram estruturais e que não houve problemas nos controles, sustentando, assim, que explicações "de fora", "estruturais", "externalistas" não afetaram os testes. Os DCOs fizeram, segundo ele, um excelente controle "quase sem condições". Um ponto ressaltado por esse dirigente é que, em relação ao anti-doping, passavam por uma "época de desconfiança geral" em decorrência das recentes descobertas de doping estatal na Rússia, o que teria dificultado algumas ações da sua equipe.

Tais controvérsias relacionadas aos DCOs, sobretudo, nos possibilitaram compreender que, durante os anos que antecederam os Jogos Olímpicos do Rio de Janeiro, considerando o descrito acima, o trabalho de constituição da conformidade com a WADA era uma agenda que incidia de maneira mais incisiva sobre o funcionamento da $A B C D$ do que ao COL da Rio2016. Desse modo, é possível entender que os modos de agir da WADA frente à ABCD eram também uma forma de distanciar as ações das instituições antidopagem (WADA e NADOs) das instituições do universo esportivo (sistema $\mathrm{COI} / \mathrm{COB} / \mathrm{COL}$ ). A seguir, apresentamos mais dois exemplos de exigências da WADA para que a ABCD mantivesse a conformidade.

\subsection{INTERESSES INDISPENSÁVEIS (MAS NEM TANTO) PARA OS JOGOS RIO 2016}

Nesse processo de translação marcado pela reunião de interesses e pela tentativa de desvio ou distanciamento de interesses de agentes e instituições antidopagem, como descrevemos anteriormente, é que foram também produzidos dois importantes dispositivos na luta contra a dopagem esportiva brasileira: o Código Brasileiro Antidopagem e a Justiça Desportiva Antidopagem, composta por um Tribunal e por uma Procuradoria específicos. Essas eram exigências da WADA para

15 RUMSBY, Bem. Rio 2016 Olympics: Anti-doping branded 'worst' in Games history. Disponível em: https://www. telegraph.co.uk/olympics/2016/08/17/rio-2016-olympics-anti-doping-branded-worst-in-games-history/. Acesso em: 15 jul. 2018.

16 Responsável por auxiliar o DCO na notificação do atleta para a realização do controle. 
a conformidade da $A B C D$, que, no caso brasileiro, tinha no seu horizonte próximo à realização das Olimpíadas. Contudo, apenas um deles foi instituído a tempo dos Jogos de 2016.

A conformidade dependia da existência de um Código Nacional constituído para garantir a eficácia do Código Mundial Antidopagem da WADA, tal como ratificado na Convenção Internacional Contra o Doping no Esporte (UNESCO, 2005). A maioria dos artigos do Código Internacional foram contemplados na versão brasileira, contudo, alguns foram modificados por não estarem adequados à legislação local, havendo concessões ou permeabilidades frente às dinâmicas da governança local. O principal exemplo disso foi a supressão do banimento do esporte que está presente no código internacional, mas no documento brasileiro ficou definida como pena máxima 30 anos de afastamento. Wurtz assim explicou essa adaptação:

\begin{abstract}
Aí [os atores da WADA] disseram: 'Mas vocês puseram 30 anos aqui, é banimento' [o que consta no Código Mundial]. [Eu disse:] 'Não, o Brasil não tem pena de banimento garantida na Constituição.' [WADA:] 'Não, mas é assim no mundo todo.' [eu:] 'Não, não, não... estou até mudando isso no comitê de ética da CBF, que tinha um negócio de banimento.' Eu lembrei lá pro presidente [da CBF]: 'Não tem [banimento] no Brasil. A pena máxima no Brasil é 30 anos'. Claro, você pode dizer: 'É o Código internacional, vou pôr'. Um advogado juvenil vai derrubar na justiça. Nem entro no mérito. Não é nem minha opinião, embora eu ache que não deve mesmo [ter banimento]. (Entrevista com João Pedro Wurtz)
\end{abstract}

O Código Brasileiro foi aprovado em maio de 2016 (BRASIL, 2016a) e assinado pela presidenta Dilma Rousseff às vésperas do julgamento de seu afastamento interino pelo Senado Federal. Em vistas da iminência da saída da presidenta e da provável mudança de governo, o que faria com que os atores da ABCD fossem trocados (o que de fato aconteceu), Wurtz agiu nos últimos momentos de governo para aprovar o Código Brasileiro Antidopagem. Em entrevista, ele relatou como mobilizara uma série de aliados para que a $A B C D$ não fosse descredenciada por não conformidade, mostrando como neste momento de prova a agência brasileira se mobilizou e agiu para aderir às exigências da WADA.

Enfim nós terminamos tudo para encaminhar à presidente no limite. Eram seis agências do mundo que estavam 'penduradas': Brasil, Espanha, França, Bélgica e México. No limite, sexta, 18 de março [de 2016], seis da tarde: quem não tivesse feito, estava em não conformidade. Eu disse: 'Não vai acontecer conosco'. [...] Aí terminamos na quarta-feira, dez horas da noite. Naquela quarta-feira que a presidente teve vazada aquela história dela da nomeação do presidente Lula como Ministro. Palácio cercado, tentativa de invasão. Levaram a presidenta para o [Palácio do] Alvorada às quatro horas da tarde. Nessa noite, eu saí [do Ministério] da Casa Civil às dez horas da noite. E alguém levou para o Alvorada a MP [Medida Provisória] que ela precisava assinar pra publicar no dia seguinte. A minha portaria já tinha ido para o Diário Oficial [DOU]. [...] Vinha para a casa, me liga o cara lá do DOU. [ele disse:] 'Nós temos um problema, a sua portaria é muito grande, tem 90 páginas. Pode ser complicado na edição extra.' [...] O DOU para a presidência fecha à meia-noite. Pensei: não vai rolar. Dez horas. O mais provável, se ela assinar, vai ser [edição] extra. O problema é que o extra com 80 páginas é mais complicado. 'Então, [ele disse] a gente pode publicar sexta'. 'Muito risco': eu consegui o mais difícil que é a presidente assinar a MP no âmbito da crise e a minha portaria assinada por mim. Dá um azar, não sai e a gente cai [fica não conforme] por isso... Nunca ninguém vai entender. Aí o cara disse: ‘Eu meto a sua portaria hoje e ela sai 
no DOU de amanhã. E quando sai a da presidente, sai edição extra.'; [eu:] 'Cara, vão achar que eu sou doido porque essa portaria no DOU sem a MP. Vão dizer: está maluco'. O cara disse que é melhor. Eu disse: 'Publica!' E ele publicou. A presidente assinou a portaria no meio da madrugada. Alguém me mandou um WhatsApp com a assinatura dela na minha MP 718. [...] De tarde, saiu e eu mandei essa mensagem pra todo mundo. Um monte de cumprimento, até do Nuzman. Caíram três dos seis [países]. A WADA colocou seis NADOs com a cabeça na guilhotina, vou tomar um café o volto dia 18 às seis da tarde. Quem continuasse com a cabeça, eles iam soltar a guilhotina. No meio daquele momento, ela assinou, não perdeu o foco. (Entrevista com João Pedro Wurtz, grifo nosso)

A afirmação em tom de surpresa "até do Nuzman" não é gratuita como pudemos explicitar anteriormente a respeito da translação de interesses (distanciamentos e distinções entre os coletivos de aliados), especialmente quando associada ao relato de Wurtz sobre a pressão exercida pela WADA a respeito do Código, que, nas suas palavras, estava "com a cabeça na guilhotina". Apesar da autonomia e da independência, no trabalho para conquistar a conformidade da NADO brasileira e, com isso, o sistema WADA/ABCD estar atuante e reconhecido durante os Jogos Olímpicos e Paralímpicos que ocorreriam naquele mesmo ano, dois interesses pareciam ser indispensáveis a partir dos quais se reuniria uma comunidade antidopagem: o Código e a Justiça Antidopagem nacionais.

Entretanto, muito embora a existência e o funcionamento de uma Justiça Antidopagem nacional também fossem exigências da conformidade, esse segundo dispositivo da luta que fazia unir uma comunidade de atores heterogêneos antidopagem não ficou pronto para a realização dos Jogos Olímpicos de 2016, apesar da pressão da WADA relatada por Wurtz. A força da pressão dos interesses da WADA como "um ator que faz fazer" - um mediador - estava conectada à realização dos Jogos. Porém, a imposição de elementos da governança internacional estava diante da necessidade de manter certa autonomia dos atores e instituições nacionais, revelando, além disso, que estava colocado um interesse indispensável ainda mais candente do que a própria agenda da WADA: a realização dos Jogos Olímpicos. Um cenário de abandono dos Jogos em março de 2016 era pouco tangível, assim podemos considerar que o calendário havia produzido uma forma de irreversibilidade. Assim, se esse equilíbrio de forças fosse instaurado (impossibilidade de cancelamento dos Jogos), a WADA se encontrava em posição de fragilidade.

Por essa razão, apenas passados os Jogos é que a WADA acabou por declarar a não conformidade da $A B C D$, impedindo-a de atuar por seis meses (de novembro de 2016 até abril de 2017) em decorrência da não criação da Justiça Desportiva Antidopagem. Assim como a criação e o funcionamento da ABCD foi um processo lento (cerca de cinco anos), a constituição do tribunal exclusivo antidopagem também não foi rápida. O governo federal estava em um momento difícil e a efetivação do tribunal ocorreu quase um ano após a derrubada da presidenta do Brasil e a posse do vice.

$O$ dirigente da ABCD contou as dificuldades para tal concepção, um momento conflituoso que revelou os atores que agiam para isso. Wurtz comentou que convidou "os juízes que atuavam em tribunais esportivos do Brasil" para uma reunião. Segundo esse dirigente, em um primeiro momento, os juízes do esporte não 
queriam a existência desta corte, e até duvidavam que a WADA a tivesse exigido. Segundo o dirigente da ABCD - que neste momento, em março de 2016, ainda estava "conforme" -, ele buscou se aproximar desses juízes, cuja preocupação residia no fato de que a existência de um tribunal antidopagem diminuísse os processos dos tribunais esportivos, o que faria com que diminuísse seu espaço de atuação e a sua importância dentro da justiça esportiva. Assim, se tornava fundamental a associação da agência brasileira com os juízes que atuavam nos tribunais esportivos.

Os casos de doping eram julgados na época pelo Superior Tribunal de Justiça Desportiva (STJD), mas a agência mundial entendeu que era necessário haver uma instância específica, a qual seria importante para a independência e a autonomia dos julgamentos. Além disso, outro argumento apresentado era o de que a legislação antidopagem é ampla e complexa, e, portanto, os atores deste tribunal deveriam aprofundar os conhecimentos sobre o tema para poder julgar os atores com mais correção. De todo modo, a WADA pode apelar para modificar julgamentos se eles não foram conformes ao Código Mundial.

A segunda gestão da agência nacional, formada após o impeachment por aliados de Deschamps, ao saber que a $A B C D$ ficaria em não conformidade em outubro de 2016, mobilizou uma série de atores - membros da ABCD, Ministro do Esporte, embaixador do Brasil e Ronaldo Deschamps - que se deslocaram até a sede da WADA no Canadá com o interesse de convencê-la a manter a ABCD em conformidade. Esta ação, relatada por um dirigente da $A B C D$, não obteve o resultado pretendido, fazendo, assim, com que a segunda gestão se defendesse das críticas utilizando a estratégia de culpar a primeira gestão de não ter cumprido com os prazos da WADA para o Tribunal. Esse argumento foi empregado porque consideraram que essa crítica seria justificada pelo pouco tempo, cerca de cinco meses, em que estavam no controle da ABCD.

A lei que criou o tribunal exclusivo para analisar denúncias de uso de doping em práticas esportivas foi sancionada em 28 de julho de 2016 (BRASIL, 2016b), porém o tribunal só ficou efetivo em 2017, com a publicação do seu regimento interno no Diário Oficial. A efetivação dos julgamentos se deu a partir de negociações da ABCD com membros da Justiça Desportiva existente, o Conselho Nacional do Esporte, o Conselho dos Atletas e as Confederações Esportivas. O Tribunal alterou as práticas de julgamento por doping, que eram realizadas até então pelo STJD, e atores do grupo antidopagem da Rio2016 ocuparam ao menos um de seus nove assentos, aproximando-se da $A B C D$, que era, então, como dito, comandada por atores próximos a ele. Essas alianças e aproximações da antidopagem brasileira com as práticas demandadas pela WADA puseram a ABCD novamente em conformidade com o Código Mundial.

Descrições como essas trazidas acima mostram que, no caso da governança local, a constituição de uma comunidade antidopagem entrelaçada com a agenda da governança internacional parece ter obtido maior estabilidade quando os Jogos Olímpicos ocupavam um lugar de articulação como interesse indispensável para os atores heterogêneos envolvidos. Se, por um lado, a ABCD - "com a cabeça na guilhotina" - atuava para atender as demandas da WADA e ficar em conformidade, 
essa agência internacional também fez concessões de seus interesses, como no caso da manutenção da conformidade durante dos Jogos mesmo frente à ausência de um Tribunal Antidopagem nacional em funcionamento. Passado o período de realização dos Jogos a concessão foi retirada e a ABCD foi declarada não conforme, o que reforça o lugar da competição internacional como uma forte articuladora de interesses nas governanças nacionais e internacionais, portanto, e de estabilização da comunidade antidopagem.

\section{CONSIDERAÇÕES FINAIS}

A conformidade se configura como um instrumento utilizado pela agência mundial para a aderência dos capturados, as agências nacionais, às exigências do "capturador" (CHATEAURAYNAUD, 2017), a WADA, que ativa a exigência de conformidade como um imperativo de justificação na relação de poder e de criação de assimetrias entre as instituições. No entanto, a conformidade não se resume a uma atividade técnica de alinhamento ou adequação de normas, padrões, processos e de regras para atender a critérios exógenos de governança internacional.

No caso do presente estudo, o trabalho de conquista da conformidade da $A B C D$ reflete um processo de translação para a estabilização - funciona como uma caixa-preta para atores que não estão familiarizados com a política brasileira (como a WADA) - dessa comunidade nacional protagonizada por uma agência de Estado (a $A B C D$ ) e, portanto, na tessitura de uma política pública de Estado, afinal trata-se de uma Secretaria Nacional com programas e projetos de ação que se materializam na relação com um Código e um Tribunal, estes existentes e atuantes nas formas de Leis e Decretos. No entanto, não é tão óbvio que a $A B C D$ representa o Estado. Justamente, tudo é feito para que as NADOs sejam independentes dos Estados (esta é uma exigência que aumentou com o caso russo). Como muitas NADOs, a ABCD deve seguir os requisitos da WADA, mas é limitada pela situação local.

Para que esse protagonismo da ABCD seja acreditado ao longo do tempo e do espaço é fundamental um trabalho de estabilização das associações (aliados e seus interesses). Pelo que pudemos aprender nas descrições na seção anterior deste estudo, tal trabalho social de conformidade envolveu:

1. O trabalho de reunir (mais do que unir) interesses de atores heterogêneos, não estando definido a priori qual deles tem capacidade para desenvolver controles antidopagem. Apesar da ABCD (aliados mais articulados com a WADA) ter sido constituída a tempo para coordenar controles nos Jogos Rio2016, foi a Comissão Antidopagem do COL Rio2016 que assumiu o controle (antigos aliados da antidopagem nacional mais vinculados ao $\mathrm{COI} / \mathrm{COB}$ ), colocando a $\mathrm{ABCD}$ no lugar de suporte.

Nesse sentido, o calendário foi decisivo, o que convida a aproximar a análise de uma sociologia da promessa (TRABAL; COLLINET; TERRAL, 2017). Portanto, esta é uma derrota para a WADA. No final das contas, o Brasil é um dos únicos países que dissuadiu a WADA, e a pena foi o não cumprimento em outubro. Nesse sentido, há uma vontade da WADA de atuar como "capturador", mas que 
não funcionou nesse caso. Podemos dizer que o "capturador" ficou "preso na sua armadilha".

2. O trabalho para impor interesses indispensáveis comuns na estabilização de uma comunidade antidopagem esteve vinculado à realização dos Jogos Rio2016, mas não numa única direção (princípio da simetria). Se, de um lado, a pressão da WADA para criação e implementação de Código e Tribunal nacionais se fazia sentir mais pela proximidade da realização dos Jogos, de outro, a própria agência internacional teve que fazer concessões na ausência do Tribunal em funcionamento.

Essa reflexão provoca o interesse de entender o que a WADA aprendeu com o caso brasileiro. É por isso que a WADA, atualmente, não se contenta mais com promessas e pede garantias? Nesse sentido, uma pesquisa com funcionários da WADA, o que não sucedeu nesse estudo, seria interessante. Ademais, cabe citar outras limitações da pesquisa, sobretudo aquelas relacionadas aos acessos do pesquisador no campo. Este era um iniciante no mundo da antidopagem e, por conta disso, não obteve acesso a todos as práticas e grupos sociais da antidopagem. Além disso, o doping é um tema delicado sobre o qual os atores, por vezes, não se sentem confortáveis em falar.

No que se refere à questão da temporalidade, mais precisamente da irreversibilidade, pode-se entender que foi ela que fez com que a WADA cedesse, já que não é factível parar as Olimpíadas alguns meses antes. Então, a $A B C D$ não foi punida antes dos Jogos e o movimento esportivo ganhou também porque o tempo estava ao seu lado. Assim, podemos concluir que conformidade é um trabalho social constante que dialoga, ao longo do tempo e do espaço, com ações de estabilidade e de reversibilidade de uma comunidade nacional de luta contra a dopagem no esporte. No caso do Brasil, essa comunidade foi composta de atores heterogêneos mostrados como um coletivo para o COI e a WADA para realizar os Jogos.

A heterogeneidade, os conflitos entre os atores e as tensões políticas que marcaram este episódio são, em última análise, uma força e uma fraqueza. Uma força porque a WADA foi forçada a entender que, além das promessas e da apresentação da existência de uma comunidade antidopagem, contingências locais poderiam surgir. Graças à irreversibilidade dos Jogos, os atores brasileiros puderam impor sua concepção de combate à dopagem contra um sistema mundial. Mas também é um ponto fraco, pois a independência da luta contra a dopagem foi adiada. Aqueles que consideram isso uma vitória devem admitir que durou pouco. Podemos nos perguntar que vestígio isso vai deixar. A confiança nas promessas brasileiras pode ser prejudicada. Mas, ao mesmo tempo, a questão da dopagem para os Jogos de 2016 foi marcada sobretudo por outra ação que permitiu criar um desvio: a participação de atletas russos nesta competição. 


\section{REFERÊNCIAS}

BARTHE, Yannick et al. Sociologia pragmática: guia do usuário. Sociologias. v.18, n.41, p.84-129, 2016. Disponível em: https://www.scielo.br/scielo.php?script=sci arttext\&pid=S1517-45222016000100084 Acesso em: 12 jan. 2021.

BRASIL. Decreto 7.630, de 30 de novembro de 2011. Altera o Decreto $n^{\circ} 7.529$, de 21 de julho de 2011, para prever a Autoridade Brasileira de Controle de Dopagem na Estrutura Regimental do Ministério do Esporte. Brasília, DF: Presidência da República, 2011. Disponível em:http://www.planalto.gov.br/ccivil 03/ Ato2011-2014/2011/Decreto/D7630. htmimpressao.htm. Acesso em: 12 jan. 2021.

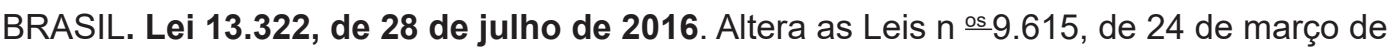
1998, que institui normas gerais sobre desporto... Brasília, DF: Presidência da República, 2016a. Disponível em: http://www.planalto.gov.br/ccivil 03/ Ato2015-2018/2016/Lei/L13322. htm. Acesso em: 12 jan. 2021.

BRASIL. Decreto 8.692, de 16 de março de 2016. Regulamenta o controle de dopagem a que se refere a Lei $n^{\circ} 9.615$, de 24 de março de 1998, que institui normas gerais sobre desporto. Brasília, DF: Câmara dos Deputados, 2016b. Disponível em:http://www2.camara. leg.br/legin/fed/decret/2016/decreto-8692-16-marco-2016-782563-publicacaooriginal149755-pe.html. Acesso em: 12 jan. 2021.

BRASIL. Ministério da Cidadania. Autoridade Brasileira de Controle de Dopagem - ABCD. Código Brasileiro Antidopagem. Brasília, DF, 2016c. Disponível em: https://www.gov.br/ abcd/pt-br/composicao/regras-antidopagem-legislacao-1/codigos/copy of codigos/codigo brasileiro antidopagem aprovado cne diagramado jan 2021.pdf. Acesso em: 29 jul. 2018.

CHATEAURAYNAUD, Francis. Les asymétries de prises. Des formes de pouvoir dans un monde en réseaux. Paris: Documents du GSPR, EHESS, mars 2006.

CHATEAURAYNAUD, Francis. A captura como experiência: investigações pragmáticas e teorias do poder. Revista Brasileira de Ciências Sociais. Tradução de Diogo Silva Corrêa. v.32, n.95, p.1-21, 2017. Disponível em: https://www.scielo.br/scielo.php?script=sci arttext\&pid=S0102-69092017000300502\&lng=en\&nrm=iso\&tlng=pt . Acesso em: 12 jan. 2021.

DEMESLAY, Julie. Harmoniser la lutte antidopage: quelques critiques d'une gouvernance mondiale. L'Homme \& la Société, v.199, n.1, p.145-158, 2016. Disponível em: https://www. cairn.info/revue-l-homme-et-la-societe-2016-1-page-145.htm. Acesso em: 12 jan. 2021.

DEMESLAY, Julie. L'institution mondiale du dopage: sociologie d'un processus d'harmonisation. Paris: Pétra, 2013.

DEVIDE, Fabiano Pries; VOTRE, Sebastião Josué. Doping e mulheres no esporte. Revista Brasileira de Ciências do Esporte, v.27, n.1, p.123-138, 2005. Disponível em: http://www. revista.cbce.org.br/index.php/RBCE/article/view/138 . Acesso em: 20 abr. 2021.

HANSTAD, Dag Vidar; SMITH, Andy; WADDINGTON, Ivan. The Establishment of the World Anti-Doping Agency: A study of the management of organizational change and unplanned outcomes. International Review for the Sociology of Sport, v.43, n.3, p.227-249, 2008. Disponível em: https://journals.sagepub.com/doi/abs/10.1177/1012690208100552 Acesso em: 20 abr. 2021.

HOULIHAN, Barrie. Achieving compliance in international anti-doping policy: An analysis of the 2009 World Anti-Doping Code. Sport Management Review, v.17, n.3, p.265-176, 2014. Disponível em: https://doi.org/10.1016/j.smr.2013.10.002 Acesso em: 20 abr. 2021. 
LATOUR, Bruno. Ciência em ação: como seguir cientistas e engenheiros sociedade afora. São Paulo: UNESP, 2000.

LATOUR, Bruno. A esperança de Pandora: ensaios sobre a realidade dos estudos científicos. Bauru, SP: EDUSC, 2001.

LATOUR, Bruno. Jamais fomos modernos: ensaio de antropologia simétrica. Rio de Janeiro: Nova Fronteira, 1994.

LATOUR, Bruno. Reagregando o social: uma introdução à teoria do ator-rede. São Paulo: EDUSC, 2012.

MARCUS, George. Etnografia en/del sistema mundo: o surgimento de la etnografia multilocal. Alteridades, v. 11, n. 22, p. 111-127, jul./dez. 2001. Disponível em: https:// alteridades.izt.uam.mx/index.php/Alte/article/view/388/387. Acesso em: 12 jan. 2021.

PERERA, Eric; GLEYSE, Jacques. O doping ao longo do século XX na França: representações do puro, do impuro e do segredo. Revista Brasileira de Ciências do Esporte, v.27, n.1, p.55-74, 2005. Disponível em: http://www.revista.cbce.org.br/index.php/ RBCE/article/view/134. Acesso em: 20 abr. 2021.

SILVA, Méri Rosane Santos da. Doping: consagração ou profanação. Revista Brasileira de Ciências do Esporte, v.27, n.1, p.9-22, 2005. Disponível em: http://www.revista.cbce.org.br/ index.php/RBCE/article/view/131. Acesso em: 20 abr. 2021.

SILVEIRA, Viviane Teixeira; RIGO, Luiz Carlos. O programa Passaporte Biológico: considerações sobre o governo dos atletas. Movimento, v.21, n.2, p. 495-506, 2015. Disponível em: https://doi.org/10.22456/1982-8918.48211. Acesso em: 20 abr. 2021.

TRABAL, Patrick; COLLINET, Cécile; TERRAL, Philippe. Faire preuve d'interdisciplinarité: Un mot d'ordre, ses interprétations et ses ajustements. Terrains \& travaux, n.30, p.209229, 2017. Disponível em:https://www.cairn.info/revue-terrains-et-travaux-2017-1-page-209. htm?ref=doi. Acesso em: 10 fev. 2021.

UNESCO. International Convention against Doping in Sport. Paris, 2005. Disponível em: https://unesdoc.unesco.org/ark:/48223/pf0000142594.page=2 Acesso em: 22 jun. 2021.

VASQUES, Daniel Giordani. Como manter o ‘jogo limpo'? associações, harmonizações e hibridez na constituição da antidopagem esportiva. 2018. 204f. Tese (Doutorado) - Programa de Pós-graduação em Ciências do Movimento Humano. Universidade Federal do Rio Grande do Sul. Porto Alegre, 2018. Disponível em: https://lume.ufrgs.br/ handle/10183/194369 Acesso em: 20 jun. 2021.

VAZ, Alexandre Fernandez. Doping, esporte, performance: notas sobre os "limites" do corpo. Revista Brasileira de Ciências do Esporte, v.27, n.1, p.23-36, 2005. Disponível em: http:// www.revista.cbce.org.br/index.php/RBCE/article/view/132. Acesso em: 20 abr. 2021.

WADA - WORLD ANTI-DOPING AGENCY. Código Mundial Antidopagem. Lisboa: ADoP, 2015. Disponível em: https://www.WADA-ama.org/sites/default/files/resources/files/codigo mundial_antidopagem_2015.pdf. Acesso em: 12 jan. 2021.

WADA - WORLD ANTI-DOPING AGENCY. Relatório de Observadores Independentes da WADA. Jogos Olímpicos e Paralímpicos Rio de Janeiro 2016. Disponível em: https://www. wada-ama.org/sites/default/files/resources/files/rio2016 io team report 26102016.pdf . Acesso em: 12 jan. 2021. 
ZUBIZARRETA, Ekain; DEMESLAY, Julie. Power relationships between the world antidoping agency and national anti-doping agencies and their effects on anti-doping.

Performance Enhancement and Health, v. 8, n. 4, 2020. Disponível em: https://www. sciencedirect.com/science/article/abs/pii/S2211266920300256?dgcid=rss_sd_all. Acesso em: 12 jan. 2021. 
Abstract: 'Compliance' is an instrument used by the World Anti-Doping Agency (WADA) for national agencies to adhere to the requirements of the captor. Based on pragmatic sociology, we describe the actions of actors working on 'compliance' at the Brazilian Anti-Doping Agency (ABCD), in view of the Rio 2016 Olympics and Paralympics, and the development of an 'anti-doping culture.' Using multi-situated ethnography, we describe the work of mediators that transform, translate, distort and modify their interests. As sources of controversies, we chose ABCD's creation and operation; the approval of the Brazilian Anti-Doping Code; and the establishment and operation of the Anti-Doping Sports Justice. ABCD's social work in achieving 'compliance' reflects a process of translation to stabilize this national anti-doping community led by a state agency and, therefore, in the making of a Public Policy.

Keywords: Doping in Sports. Sports. Public Policy. Sociology.

Resumen: La 'conformidad' es un instrumento utilizado por la Agencia Mundial Antidopaje (WADA) para que las agencias nacionales se adhieran a las exigencias del captor. En este artículo describimos, con base en la sociología pragmática, las acciones de los actores en el trabajo de constitución de la 'conformidad' de la Autoridad Brasileña de Control de Dopaje (ABCD), teniendo en vista la realización de los Juegos Olímpicos y Paralímpicos de Río 2016 y el desarrollo de una 'cultura antidopaje'. A partir de una etnografía multisituada, buscamos describir el trabajo de los mediadores, transformando, traduciendo, distorsionando y modificando intereses. Escogimos como fuentes de controversias la creación y el funcionamiento de la ABCD; la aprobación del Código Brasileño Antidopaje; y la constitución y funcionamiento de la Justicia Deportiva Antidopaje. El trabajo social de conquista de la 'conformidad' de la ABCD refleja un proceso de traslación para la estabilización de esta comunidad nacional antidopaje, protagonizada por una agencia del Estado y, por lo tanto, en la composición de una Política Pública.

Palabras clave: Doping en los Deportes. Depor s. Política Pública. Sociología. 


\section{LICENÇA DE USO}

Este é um artigo publicado em acesso aberto (Open Access) sob a licença Creative Commons Atribuição 4.0 Internacional (CC BY 4.0), que permite uso, distribuição e reprodução em qualquer meio, desde que o trabalho original seja corretamente citado. Mais informações em: http://creativecommons.org/licenses/by/4.0

\section{CONFLITO DE INTERESSES}

Os autores declararam que não existe nenhum conflito de interesses neste trabalho.

\section{CONTRIBUIÇÕES AUTORAIS}

Daniel Giordani Vasques: Autor do projeto de pesquisa. Produção e análise de dados. Escrita e análise do texto. Revisão.

Mauro Myskiw: Escrita e análise do texto. Revisão.

Patrick Trabal: Escrita e análise do texto. Revisão.

Marco Paulo Stigger: Orientação do trabalho. Escrita e análise do texto. Revisão.

\section{FINANCIAMENTO}

O presente trabalho foi realizado com apoio da Coordenação de Aperfeiçoamento de Pessoal de Nível Superior - Brasil (CAPES) - Código de Financiamento 001. "This study was financed in part by the Coordenação de Aperfeiçoamento de Pessoal de Nível Superior - Brasil (CAPES) - Finance Code 001"

\section{ÉTICA DE PESQUISA}

O projeto de pesquisa foi encaminhado e aprovado pelo CEP da UFRGS, número protocolo CAAE 63101516.2.0000.5347, Número do Parecer: 2.081.732.

\section{COMO REFERENCIAR}

VASQUES, Daniel Giordani; MYSKIW , Mauro; TRABAL,Patrick; STIGGER, Marco Paulo. A antidopagem em face das demandas da agência mundial: uma etnografia da 'conformidade'. Movimento (Porto Alegre), v.27, p.e27035, jan./dez. 2021. Disponível em: https://seer.ufrgs.br/Movimento/article/view/111756. Acesso em: [dia] [mês abreviado]. [ano]. DOI: https://doi.org/10.22456/1982-8918.111756

\section{RESPONSABILIDADE EDITORIAL}

Alex Branco Fraga*, Elisandro Schultz Wittizorecki*, Ivone Job*, Raquel da Silveira* *Universidade Federal do Rio Grande do Sul, Escola de Educação Física, Fisioterapia e Dança, Porto Alegre, RS, Brasil. 